\title{
L'aposta per la transcendència materialista: un recorregut per la història del transhumanisme
}

\author{
Ferran Sánchez Margalef \\ Universitat de Barcelona \\ ferran.sanchez@ub.edu
}

Data de recepció: $13-4-2021$

Data d'acceptació: 27-9-2021

\begin{abstract}
Resum
Gràcies a l'aposta tecnològica de les societats actuals i també a la globalització que comporta, el moviment transhumanista, visiblement heterogeni, està començant a ser (re)conegut a tot el globus terraqüi i a adquirir una enorme volada. Això no obstant, malgrat que la materialització de les fites transhumanistes només siguin possibles en les societats postmodernes, l'origen del transhumanisme bé pot anar més enllà del que anomenem societat contemporània. En aquest article s'explora l'origen del transhumanisme partint de les tres següents hipòtesis: a) el transhumanisme com un fenomen típicament postmodern; $b$ ) el transhumanisme com a herència de la tradició renaixentista secular; c) el transhumanisme com a tret identificatiu de la naturalesa humana.
\end{abstract}

Paraules clau: materialisme; posthumanisme; transhumanisme; transcendència

\section{Abstract. In support of materialist transcendence: A journey through the history of transhumanism}

Thanks to the technological advances of today's societies and also to the globalisation that this involves, the transhumanist movement, which is visibly heterogeneous, is starting to be recognised around the world, and becoming increasingly widespread. However, although the materialisation of transhumanist achievements is only possible in postmodern societies, the origin of transhumanism may well go beyond what we call contemporary society. This article explores the origin of transhumanism based on the following three hypotheses: a) transhumanism as a typically postmodern phenomenon; b) transhumanism as a legacy of the secular Renaissance tradition; and c) transhumanism as an identifying feature of human nature.

Keywords: materialism; posthumanism; transhumanism; transcendence

\section{Sumari}

\section{Punt de partida}

2. El transhumanisme com a fenomen típicament postmodern

3. L'arribada de l'humanisme, l'home al centre de l'univers
4. El transhumanisme, inherent a la humanitat

5. Consideració final

Referències bibliogràfiques 


\section{Punt de partida}

La societat occidental es troba en un punt d'inflexió en el qual molts dels discursos que fins ara l'han sostingut han entrat en crisi. Lyotard ja adverteix d'aquest fenomen quan assenyala que, sota el paradigma de relativitat actual, els metarelats que durant la modernitat havien mostrat un camí a l'home han perdut la preponderància de què havien gaudit fins a la data (Lyotard, 2004).

Com a conseqüència, els textos acadèmics que busquen analitzar i entendre la realitat utilitzen conceptes com postideologic o postmodern per referir-se a la nostra època. No obstant això, de la mateixa manera que alguns d'aquests relats han començat a perdre preponderància, d'altres han irromput amb força i han fet trontollar el taulell polític, econòmic i social. Aquest és el cas del relat (és a dir, de la fonamentació històrica en la construcció de la cosmovisió) que aquí ens ocupa: el transhumanista.

Quan parlem de transhumanisme $(\mathrm{H}+)$, ens estem referint a un concepte polièdric que evoca diferents connotacions segons com l'enfoquem. Bostrom el defineix així:

moviment cultural, intel-lectual i científic que afirma el deure moral de millorar les capacitats físiques i cognitives de l'espècie humana i aplicar a l'home les noves tecnologies, amb la finalitat que es puguin eliminar els aspectes no desitjats i no necessaris de la condició humana: el patiment, la malaltia, l'envelliment i, fins i tot, la condició mortal. (Bostrom, 2003)

Així i tot, malgrat que sovint els autors a l'hora de definir el terme solen utilitzar el mot moviment, el transhumanisme també esdevé, en si mateix, una transformació (un canvi de paradigma), una realitat (palpable i concreta a través de les fites científiques i tecnològiques), un corrent polític, tecnològic i cultural (que amaga un pensament concret de la humanitat i del món), un fenomen (que com a tal només pot ser analitzat a partir de les interrelacions i manifestacions que l'entrellacen amb els subjectes), una via (cap al posthumanisme) o un relat (com a narració estructurada de l'origen de l'anhel de transcendència).

En aquesta última accepció —el transhumanisme com a relat- centrarem la nostra atenció al llarg del text amb l'objectiu d'albirar quines han estat les narracions que han acabat constituint $\mathrm{i}$ inspirant aquesta cosmovisió. Com a corrent de pensament que aspira a l'hegemonia cultural, el H+ cerca la seva fonamentació i legitimació en determinades fites de la tradició. Així doncs, a continuació farem un recorregut històric, sense ànim d'esdevenir exhaustius, per explorar, d'una banda, fins a quin punt les arrels del transhumanisme aprofundeixen en la història del pensament occidental $i$, de l'altra, com justifica la seva causa i basteix el propi discurs.

Abans d'entrar en el cos de l'exposició, cal apuntar que moltes de les referències que aportarem no són una reconstrucció cronològica de les fites humanes que han fet possible el transhumanisme, sinó que representen un viu 
exemple de les tres tesis que s'exposaran i es defensaran a continuació, apriorísticament incompatibles entre elles:

a) El transhumanisme com un fenomen típicament postmodern.

b) El transhumanisme com a herència de la tradició renaixentista secular.

c) El transhumanisme com a tret identificatiu de la naturalesa humana.

Com es pot apreciar, les dues primeres tesis apunten que el transhumanisme, d'una manera o d'una altra, és aliè a la naturalesa humana, mentre que l'última vincula el transhumanisme a quelcom inherent a l'home i reconeix la seva transcendència com a valor immanent a l'ésser humà.

\section{El transhumanisme com a fenomen típicament postmodern}

La primera tesi que defensarem és la del transhumanisme com a fenomen típic postmodern. Tal com apunta Octavi Fullat, podríem situar l'inici de la postmodernitat a l'any 1900, el mateix de la mort de Friedrich Nietzsche (Fullat, 2003). En aquesta línia, un dels precursors més emblemàtics del $\mathrm{H}+$, el rus Nikolai Fiódorov, que va fer algunes aportacions interessants a l'esperit transhumanista — com ara la conceptualització de «l'empresa comuna» (tasca que englobava tota la humanitat que compartia els mateixos objectius i l'enfrontava a les malalties, guerres o mort) o l'argumentació de la reanimació (Fiódorov, 1970: 5)—, també va morir en una data propera a l'inici de la nova centúria, l'any 1903. Si bé els dos autors van morir a l'inici del segle, va ser en aquesta nova era quan es van desenvolupar i es van intentar implementar, tot i que en més d'una ocasió de manera esbiaixada, els pensaments dels dos autors. Per posar-ne un exemple, igual que la cosmovisió nacional socialista va interpretar el superhome segons les seves pròpies coordenades, el transhumanisme també farà la seva pròpia hermenèutica de les famoses paraules següents: "L'home és quelcom que ha de ser superat. Què heu de fer per superar-lo? Fins ara tots els éssers han creat alguna cosa que els supera: i vosaltres voleu ser el reflux d'aquesta gran marea i recular fins a la bèstia en comptes de superar l'home?» (Nietzsche, 1983: 23). Serà, per tant, en aquest lapse anomenat postmodernitat que el transhumanisme torna a recórrer a l'existencialisme de l'alemany per projectar un nou model de superhome, en aquest cas, tecnològic.

Breument, cal apuntar que la postmodernitat és l'escenari que posa de manifest la crisi sistèmica i estructural després de l'esgotament de les vies humanistes per a la conducció i el perfeccionament de l'ésser humà. Els relats polítics, filosòfics, pedagògics, sociològics i teològics que heretàvem de la tradició humanista han patit, davant el xoc de realitat que ha suposat el darrer segle, un esgotament continu del seu discurs. La mort de Déu és l'anunciada mort de les cosmovisions, de fórmules tancades d'interpretació de la realitat. No és menys rellevant que, en un camp allunyat del filosòfic, Albert Einstein demostrés matemàticament la relativitat de l'espai-temps (Einstein, 1995). Així, l’any 1905 publicava la teoria que defensava la tesi — que seria acceptada 
més endavant- que el sistema de referència (coordenades des de les quals es defineixen els paràmetres) des del qual s'observa un fenomen és una variable determinant en el resultat final de l'anàlisi. D'aquesta manera, veiem com des de dos camps diferents s'arriba a la mateixa conclusió: les veritats absolutes s'han esvaït i la casuística dels paràmetres (com l'espai, el temps o la perspectiva individual) ocupa una posició primordial en el rumb de la investigació.

Abans d'arribar, però, definitivament a l'era relativonihilista anunciada, dues guerres mundials, seguides d'una llarga guerra freda, en què la humanitat es va veure abocada a un sinistre espiral de barbàrie, serien imprescindibles per acabar d'ofegar qualsevol mena de concepció essencialista i donar pas a una era de tall relativista, incompatible amb la tradició humanista heretada que havia dut a les atrocitats del segle xx. No hem d'oblidar que és precisament en la tradició humanista on trobem les derives idealistes i materialistes totalitàries que tindrien lloc al segle passat. En aquest sentit, una de les reflexions més lúcides queda patent a la Carta sobre el humanismo de Heidegger, on apunta que el nazisme també és fill de la tradició humanista, en esdevenir una barreja entre humanisme i brutalitat (Heidegger, 2000). És concretament en aquest punt, quan es constata on han dut els discursos humanistes del segle passat, que aquests colllapsen i queden greument ferits per abordar els reptes del nou segle.

No obstant això, també és en aquest moment en què tantes cosmovisions es troben en fallida que el transhumanisme s'alça vigorosament per reclamar materialment els desitjos i els somnis de la humanitat. Si l'aposta materialista marxista havia promès, al segle xx, la construcció del paradís a la Terra, el transhumanisme, un segle després, farà la mateixa promesa. Ara bé, si el marxisme prometia l'edèn mitjançant la concatenació d'elements que facilitarien l'accés al poder de la classe obrera en un règim d'igualtat (comunisme), el transhumanisme perseguirà la mateixa fita assegurant la democratització dels avenços científics i tecnològics. Efectivament, el transhumanisme, com el marxisme, abandona i nega l'esperit i es fixarà solament en la matèria com a variable inexcusable per transformar la realitat. De fet, la revolució transhumanista bé pot produir-se a través de la manipulació genètica, una via que esdevé com una de les més plausibles per a la concreció i la realització de les esperances transhumanistes.

En qualsevol cas, serà a través de la informatització i la digitalització dels processos biològics, de desxifrar els secrets que la naturalesa atresora i d'integrar-los tots a l'ésser humà (és a dir, a la matèria tangible que és el nostre cos) com el transhumanisme intenta(rà) fer el pas del terreny especulatiu i sensible al pràctic i aplicable que incideix i transforma la realitat. En aquest sentit, García, Turró i Vilanou apunten que el cos és un escenari polític per a la insurrecció i la profanació, com així ho proven les diferents experiències que es realitzen en l'actualitat, que porten el cos fins a l'extrem de tatuar-se o perforar-se (García Farrero et al., 2016). Una vegada s'ha obert la porta a la transformació (profanació), la integració de la tecnologia al cos humà reclamada pel transhumanisme bé pot esdevenir el següent esglaó en el decurs dels esdeveniments. 
Ras i curt, mitjançant la transformació de la matèria (cos humà), l'ésser postmodern (que deixarà de ser humà) assolirà la transcendència.

Aquí es troba la clau de volta del nou paradigma postmodern: ja no és la persona la que se situa al centre de l'univers, ara s'hi situarà la tecnologia, $\mathrm{i}$ serà l'ésser humà el que orbitarà entorn seu. Si la modernitat ha estat antropocèntrica, la postmodernitat esdevindrà tecnocèntrica (Wauthion, 1998). No es tracta, però, d'un paradigma dicotòmic binari d'humà-màquina, com la literatura i la cinematografia s'han encarregat de traslladar en més d'una ocasió, més aviat serà un escenari en què l'ésser humà s'esforçarà per connectar-se i vincular-se, a partir seu propi ésser, a la mateixa tecnologia per no restar al marge de la societat que s'està configurant entorn seu. En aquest sentit, el transhumanisme es fonamenta en una tradició que allunya de la natura l'ésser humà i el vincula a l'artificialitat. Aquesta mateixa artificialitat tecnològica serà la nota que compartiran les diverses i variades possibilitats de transcendir de l'individu, i que van des de concebre l'ésser humà com un sistema cibernètic fins a l'enginyeria genètica per modificar el mateix ADN, passant per tot un conjunt de pràctiques, com ara l'uploading (datificar el cervell humà i penjar-lo a la xarxa), la criogenització (conservació per congelació de les cèlllules i òrgans vitals) o la nanotecnologia molecular (que pot introduir estructures complexes a escala atòmica i dotar el futur individu de propietats que van més enllà de la capacitat humana), que buscaran una via pròpia en el camí de la superació de l'espècie.

Des d'aquest punt de vista, com hem anat comentant, sembla difícil que el transhumanisme es pugui desvincular del segle que l'ha vist néixer, el xx, $\mathrm{i}$ del següent que l'ha fet créixer, el xxI, perquè entronca perfectament amb moltes de les reivindicacions que, en termes globals, la humanitat ha agafat per bandera. Ens estem referint, entre d'altres, al mercantilisme i consumisme (conversió de béns en mercaderies), ja que els beneficis dels enginys transhumanistes esdevindran tan, $\mathrm{o}$ tan poc, democràtics com el funcionament de les empreses que els patentaran; o al desig de personalització, renovació i canvi constant palès en la nostra era i que està estretament lligat a la llibertat individual. Però tampoc hem d'oblidar que el transhumanisme gaudeix de bona salut entre alguns dels moviments i reivindicacions socials més extensos de la nostra era, com són el feminisme, amb el ciberfeminisme (Haraway, 1984) o l'ecologisme (Delgado Ramos, 2012: 225).

Aquí cal establir una diferenciació entre les societats anteriors a la postmodernitat (1900), que anomenarem essencialistes, i les que vindran amb aquest nou període, que rebran el nom de relativistes. A grans trets, podem dir que les societats essencialistes, emmirallant-se en el passat, es concebien com a sistemes tancats que s'organitzaven políticament i socialment sobre uns valors preestablerts. Les societats relativistes, en canvi, seran aquelles que, posant la mirada sobre el futur, faran devoció del dinamisme i li atorgaran una intrínseca idea positivista de progrés, fet que possibilitarà un canvi en la jerarquització de valors i l'aflorament de nous valors. En termes generals, les societats anteriors al segle XXI es blindaven davant el canvi, de manera allò que marca- 
va la tradició era valuós, per contra, les d'aquest nou mil-lenni veuran el que és antic com una expressió vella i desfasada i apostaran per la novetat i la immediatesa constant com a prova del progrés social mesurat materialment a través d'elements tangibles.

En poques paraules, cal assenyalar que de la mateixa manera que el transhumanisme no requerirà una imposició per la força, ja que la seva implementació esdevindrà un reclam social gràcies a l'efecte i els beneficis que assegura proporcionar, tampoc la reclamarà el sistema polític que succeeixi la democràcia. Si en les societats essencialistes va ser necessari, en la majoria de casos, un trencament brusc com ara un alçament militar o un cop d'estat per fer trontollar i ensorrar el sistema vigent (com va passar amb la Revolució Francesa o la Russa) i donar pas al següent, les societats relativistes podran assegurar aquesta transició sense haver de salvar cap problema aparent ni vessar sang, ja que en les societats relativistes no opera una única cosmovisió i, per tant, no és necessària una transició d'un sistema tancat cap a un altre, perquè és el mateix sistema obert el que cerca(rà) la performativitat. En aquest sentit, val la pena esmentar que els reptes que implica el $\mathrm{H}+$ són incompatibles amb la democràcia actual en atemptar directament contra la igualtat de l'espècie humana. Per tant, si se segueix per l'aposta materialista, s'haurà de transitar cap a una nova forma política i social d'organitzar-se.

No podem tancar aquest primer punt sense dedicar un apartat a la cibernètica com un dels precedents més clars i evidents del transhumanisme. La cibernètica va néixer l'any 1942 com a ciència que estudia l'estructura dels sistemes reguladors vinculats a dispositius de control, a la comunicació i a la teoria de sistemes en organismes vius, màquines, organitzacions o camps d'estudi, de forma sistèmica i multidisciplinària. Si la cibernètica és la que ha permès unificar $i$ sistematitzar sota un mateix llenguatge l'ésser humà i la màquina, el transhumanisme s'encarregarà de la seva hibridació. Aquí cal fer referència al professor Sanvisens, que ja va escriure l'any 1984 a Cibernètica del que és humà la següent afirmació, que continua ben present en l'actualitat, i a la qual el $\mathrm{H}+$ aspira a donar forma:

L'automatisme contemporani intenta eliminar, d'antuvi, l'esforç mental o directiu i, en definitiva, la intervenció humana en la producció. Les màquines s'autoregulen, es controlen segons les circumstàncies i finalitats, es corregeixen i reajusten, gairebé es pot dir que amb el seu autofuncionament, s’autoestructuren (...). Sembla com si assistíssim al començament d'un nou món industrial, sense obrers, sense encarregats i sense tècnics de control. (Sanvisens, 1984: 68)

El punt d'inflexió d'aquesta nova era de què parla el professor Sanvisens, segons transhumanistes com Ray Kurzweil, serà la singularitat, el moment en què les màquines disposaran d'una autonomia total (Kurzweil, 2015). 


\section{L'arribada de l'humanisme, l'home al centre de l'univers}

La segona tesi planteja que va ser en l'època del Renaixement quan es va iniciar la tradició que, presumiblement, pot acabar desembocant en el transhumanisme. Al cap i a la fi, és en aquest període històric quan es produeix un gir del pensament en què se substitueix el teocentrisme per l'antropocentrisme. La transcendència d'aquest canvi és comparable al que vol implantar el transhumanisme en desplaçar l'ésser humà pel subjecte posthumà. Va ser al llarg dels segles XIV i XV que l'ésser humà va desplaçar Déu del centre de l'univers per situar-s'hi ell mateix, un punt cabdal perquè l'home pugui ascendir en un futur fins a convertir-se, ell mateix, en la divinitat (posthumà) que al llarg d'aquest període va començar a descentrar. Situar l'home en un primer pla es pot arribar a considerar, doncs, com l'inici d'una cursa que acabarà rellevant-lo a una posició secundària en cas de triomfar les tesis i els enginys transhumanistes. Aquest és, doncs, un dels motius que porten tot un seguit d'autors a situar l'origen d'aquest moviment en l'humanisme secular (Cortina, 2017).

També Dant, considerat el primer home de tarannà renaixentista, a la Divina Comèdia fa referència a un mot semblant al de transhumanisme. Utilitza el terme transhumanar per fer referència a l'estat de joia, inexplicable mitjançant els mots, que implicava trobar-se al Paradís amb la seva estimada Beatriu. Reproduïm el fragment a continuació:

Beatriu tota amb ulls fits contemplava
les eternes rodes, i jo apartí
la vista de l'altura per mirar-la.
I, mirant-la, em vaig fer tot per dins
tal com es va fer Glauc quan tastà l'herba
que el va fer, en la mar, parent dels déus.
Aquest transhumanar mai no es podria
expressar en paraules: que l'exemple
baste a qui en té experiència per la gràcia.
Amor que el cel governes, si jo era
només la part de mi que has creat l'última,
ho saps tu, que amb la teva llum m'alçaves
(Alighieri, 2000: 855 )

No és menor el fet que siguin les accions de Dant realitzades en vida les que el fan digne d'arribar al Paradís amb la seva estimada. De la mateixa manera, la cosmovisió transhumanista també deixarà, a priori, en mans de l'ésser humà concret la seva salvació, si bé aquesta estarà en mans de la tecnologia en lloc de la fe.

A més, és al llarg del Renaixement quan es posa en marxa la tradició humanista que, a través de les diferents ramificacions, heretarem al nostre segle i que serà l'encarregada de donar llum i forma a la temptació transhumanista. Tot i l'obvietat, és necessari apuntar que, malgrat que no tots els discursos humanistes s'enfilen en la direcció transhumanista, aquest moviment és inseparable de la tradició que l'ha fonamentat. Elements com la crítica en l'ús de la raó, el 
mètode científic o els estàndards de qualitat, que han fet permeable el desenvolupament tecnològic imprescindible per a la cosmovisió transhumanista, estan estretament lligats a la tradició humanista.

D'aquesta manera, és obligada una parada al Discurs sobre la dignitat de l'home, de Pico della Mirandola, que constitueix una de les fites del Renaixement, un clàssic de l'humanisme i un precedent del transhumanisme. En aquest llibre s'expressa amb aquestes paraules:

No t'hem atorgat, Adam, ni un lloc concret ni una aparença pròpia ni cap obligació particular, amb la intenció que tinguis i posseeixis el lloc, l'aparença i les obligacions que tu mateix triïs d'acord amb el teu desig i amb el teu criteri. La naturalesa de les altres criatures es manté dins els límits d'unes lleis que els hem prescrit. Tu, lliure de cap restricció, et delimitaràs la teva segons el teu arbitri, en les mans del qual t'hem posat. T’hem situat al mig del món per tal que, des d'allí, guaitis més còmodament el que hi ha en el món que t'envolta. (Pico della Mirandola, 2001: 62)

A més, però, d'especular sobre la pròpia indeterminació de l'home, de l'espai que se li ha atribuït i de la seva capacitat per escollir el destí, afegeix:

No t'hem creat celestial ni terrenal, ni mortal ni immortal a fi que, com a lliure i noble terrissaire i escultor de tu mateix, et donis la forma que prefereixis. Podràs degenerar en les criatures inferiors, que són les bèsties; podràs regenerar-te en les criatures superiors, que són divines, seguint els criteris del teu esperit. (Pico della Mirandola, 2001: 62)

En aquesta obra també especifica que l'home és un «animal de naturalesa variada i multiforme i inestable» (Pico della Mirandola, 2001: 65), descripció $\mathrm{amb}$ la qual el transhumanisme, si bé des d'una altra perspectiva, coincidirà. No podem obviar, però, que el rerefons de l'autor en aquestes paraules és cristià —l'ésser humà té aquesta naturalesa variable perquè Déu així l'ha creat - i que, a més, en cap cas fa referència a utilitzar la ciència per millorar l'espècie. Això no obstant, Pico della Mirandola és un dels primers que identifiquen aquesta disposició o inclinació humana per a la metamorfosi com un fet inherent a la seva pròpia naturalesa, és a dir, a la voluntat de transformar-se per superar-se ell mateix d'acord amb la seva capacitat d'autodeterminació.

No hem d'oblidar tampoc que el Renaixement oferia una concepció unitària del saber: el coneixement es trobava integrat en un entramat estretament connectat. Així, les universitats medievals formaven en les arts liberals a través del trívium (gramàtica, dialèctica i retòrica) i el quadrívium (aritmètica, geometria, astronomia i música) abans d'aventurar-se en estudis superiors de teologia, filosofia, dret o medicina, per oferir una formació holística als seus estudiants (Castillo Gómez, 2002: 226). No és casualitat, doncs, que sota aquest paraigua multidisciplinari apareguessin figures com la de Battista Alberti, entre tants d'altres, que va destacar en camps avui en dia tan allunyats com són l'arquitectura, les matemàtiques, la poesia, la filosofia, la música, l'arqueologia o la pintura. L'aposta pel racionalisme i pel mètode científic que 
vindria en els segles següents, que va comportar que el coneixement es compartimentés i s'especifiqués, trencaria amb la concepció unitària del saber i faria que, en la mesura que les diferents àrees del saber s'anessin especialitzant, s'accentuessin les diferències entre elles. No obstant això, la perspectiva cibernètica i transhumanista, gràcies a la teoria de sistemes i a la digitalització de les diferents àrees del saber que possibiliten la interdisciplinarietat, torna a trobar punts de convergència entre aquestes disciplines avui dia totalment segmentades.

En aquest sentit, el triomf del materialisme transhumanista reclama aquesta interdisciplinarietat, i només serà possible en la mesura que es faci efectiva. Ja es poden començar a veure aquestes sinergies entre disciplines en diferents camps, com ara en la roboètica, que parteix d'un nexe entre robòtica i ètica; en la mateixa genètica, que està integrant aspectes informàtics amb els biològics, o en l'educatiu, on trobem la pedagogia cibernètica. En aquest sentit, la fita científica del desxiframent del genoma humà assolida recentment (i cabdal per al $\mathrm{H}+$ ) sols ha estat possible mitjançant un enfocament interdisciplinari i un treball col-laboratiu de diferents disciplines fins a fer possible reconstruir en un ordinador (digitalment) el codi genètic.

Encara en un escenari renaixentista, l'any 1543, Andreas Vesalius feia públic el seu llibre De humani corporis fabrica. Més enllà d'esdevenir un dels primers llibres d'anatomia, és altament interessant veure com equipara l'estructura humana amb una màquina en què cadascuna de les parts realitza una funció. Així inaugura una visió mecanicista de l'ésser humà que seria represa més endavant per diferents autors com Descartes o La Mettrie.

Succintament, apuntarem que amb el corrent racionalista iniciat per Descartes s'estableix un llindar — que s'anirà consolidant al llarg dels anys - que separa el cos de la ment. La separació de la res cogitans i la res extensa (Descartes, 1996) estableix una divisió entre la substància mental i la somàtica que convida a concebre-les com a ens separats. I no sols això, més enllà, va atorgar a la raó l'exclusivitat sobre la validesa de producció de coneixement i, per tant, de saber. Amb ell s'iniciarà una tradició de sotmetiment de la naturalesa per part de la humanitat, tal com ho apunta Pigem: «La voluntat de dominar la naturalesa ha format part del projecte cultural de la modernitat des de Descartes» (Pigem, 2018: 100).

Resulta també rellevant apuntar a la concepció mecanicista de l'univers i de la natura que va manifestar Descartes, que equiparava a una màquina, raonament que va quedar aparentment avalat per la física de la mecànica newtoniana $i$ es va estendre a altres disciplines més enllà de la filosofia, com és el cas de la física o de l'anatomia, amb, per exemple, la descripció de la circulació de la sang. A continuació tenim alguns exemples de la perspectiva mecanicista del pensador francès, que esdevindria més tardanament un dels pilars del transhumanisme.

Al Discurs del mètode, Descartes emfatitza la semblança entre el cos i la màquina fins al punt d'advertir que les úniques diferències entre ells són la perfecció i la complexitat, atribuïdes, totes dues, al creador suprem. Si considerem 
Déu el màxim artesà, les creacions i les màquines humanes no poden estar a la seva altura, i diu:

En saber quants autòmats diferents o màquines mòbils pot fer la indústria humana, utilitzant només molt poques peces en comparació de la gran multitud d'ossos, músculs, nervis, artèries, venes i totes les altres parts que hi ha en el cos de cada animal, considerin aquest cos com una màquina que, havent estat feta per les mans de Déu, es incomparablement més ben ordenada i té moviments més admirables que cap de les que poden ser inventades pels homes. (Descartes, 1996: 151)

En la mateixa línia, a les Meditacions metafisiques, el filòsof francès torna a establir un paral-lelisme entre el cos i la màquina quan reflexiona: "Considerava, en primer lloc, que tenia un rostre, unes mans, i tota aquesta màquina composta d'os i carn, tal com apareix en un cadàver, la qual designava amb el nom de cos» (Descartes, 2008: 109).

D'altra banda, analitzant les obres de Julien Offray de La Mettrie, cal apuntar que constitueixen també tot un referent literari en esdevenir els primers escrits sobre la hibridació de l'home. Metge de l'Exèrcit francès, La Mettrie va tenir l'oportunitat de conèixer de primera mà quin era l'estat de salut dels soldats, i a què era degut aquell estat, amb la contemplació de la part física, però també de l'anímica i l'espiritual.

La Mettrie no plantejava el dualisme cartesià de cos i ànima de manera confrontada, ja que va observar que l'estat físic condicionava plenament l'estat de l'espiritualitat, fins al punt de dependre'n. Així, discrepava del mateix Descartes, que titllava d'independent l'ànima del cos, tal com va apuntar a la cinquena part del Discurs del mètode. De tota manera, La Mettrie el justifica amb aquestes paraules: «És veritat que aquest cèlebre filòsof s'ha equivocat molt, ningú no ho discuteix. Però en definitiva ha conegut la naturalesa animal; ha estat el primer a demostrar perfectament que els animals eren pures màquines» (La Mettrie, 1983: 94).

En la seva obra més destacada, L'home màquina, La Mettrie torna a recórrer a la comparativa entre l'organisme humà (des d'un punt de vista anatòmic) $i$ el d'una màquina, fins al punt de concebre el seu protagonista com un autòmat. El metge francès es pregunta:

Encara no n'hi ha prou (...) per provar que l'home no és sinó un animal, o un agrupament de ressorts, que tots s'engalzen els uns amb els altres, sense que es pugui dir per quin punt del cercle humà ha començat la natura? Si aquests ressorts difereixen entre si, no és per res més, doncs, que pel lloc on és cadascú i per graus de força, però mai per llur natura; i per tant l'ànima no és més que un principi de moviment, o una part material sensible del cervell, que hom pot, sense por d'equivocar-se, contemplar com un ressort, com la molla principal de tota la màquina. (La Mettrie, 1983: 87-88)

Aquests serien alguns dels inicis d'un llarguíssim i extens camí, inabordable en aquest breu relat, que posarien les bases perquè, al llarg dels següents 
segles, es poguessin consolidar fites imprescindibles per al desenvolupament del transhumanisme, que van, tal com hem comentat en aquest assaig, des de la implementació del mètode científic fins al desxiframent del genoma humà. Cal aclarir, breument, que l'equiparació i hibridació d'home i màquina no és sols l'única via contemplada pel $\mathrm{H}+$ per superar l'ésser humà, però implica un dels precedents més representatius que aquesta cosmovisió trobarà en la figura del cíborg. Per tancar aquest apartat, doncs, no podem fer més que recordar la segona de les tesis sostingudes, la que situa les bases del transhumanisme en la tradició secular renaixentista, com s'ha intentat testimoniar en aquestes línies.

\section{El transhumanisme, inherent a la humanitat}

La darrera tesi situaria el transhumanisme a les albors de la civilització $i$, fins i tot, de la humanitat. Les pintures rupestres dels pobles nòmades, els gravats realitzats sobre la mateixa roca a les cavitats muntanyoses o els rituals funeraris, que mostren la preocupació vers la mort, són una bona prova que la humanitat sempre s'ha representat ella mateixa abordant de ple la transcendentalitat. És aquesta línia, la de projecció de l'ésser humà i la vida en uns altres paràmetres, la que permet estendre un fil entre el transhumanisme i els primers pobles nòmades.

De fet, els rituals funeraris en si constitueixen tota una fita per a la humanitat. Enterrar els morts implica una concepció clara de la mort (característica única de la nostra espècie) i pot mostrar també l'indici d'una creença en el més enllà. La raó per la qual es comença a practicar aquesta acció és evident: si deixes un cos sense vida a la intempèrie, serà maltractat i devorat per la natura. Si ens preguntem per què cal evitar que això sigui així quan ens estem referint a un cadàver, copsarem que un dels motius principals apunta que cal preservar el cos de cara a la següent vida, aquella que trobem després d'aquesta, perquè la conservació del cos esdevé imprescindible, ja que l'ésser humà, que es nega a acceptar la seva fi, ha de poder fer ús del cos en els camins que haurà de transitar una vegada hagi abandonat aquest món.

Una gran quantitat de la població pensa que la mort només és la porta d'entrada a una altra vida. D'aquesta manera, si ens centrem en el caràcter transcendent del transhumanisme, és a dir, en la voluntat de superar la condició mortal, podem trobar l'origen d'aquest anhel en les primeres civilitzacions funeràries que enterraven els morts i en el seu propòsit d'escapar al final biològic. No debades, si bé el desig de transcendència hi és present en ambdós casos - tant en el $\mathrm{H}+$ com en les primeres societats que enterraven els morts-, certament les civilitzacions funeràries el cercaven mitjançant vies espirituals, mentre que el transhumanisme optarà estrictament per les materials. Cal advertir, amb la intenció de no confondre el lector, que el que estem remarcant aquí no és tant la connexió entre el transhumanisme i les primeres civilitzacions funeràries com si la voluntat i la fe de transcendència de la condició mortal que nia en ambdós casos. 
Així doncs, s'ha d'aclarir que no totes les religions contemplen com una cosa imprescindible preservar el cos per a la resurrecció. Aquest és el cas, malgrat restar lluny de les primeres civilitzacions funeràries, del zoroastrisme, religió nascuda a l'imperi persa al segle vi aC (que de manera minoritària continua existint), que finalitzava els rituals funeraris deixant els cadàvers a la intempèrie perquè fossin devorats pels corbs o les hienes amb l'objectiu de no corrompre la natura.

En qualsevol cas, no hi ha cap dubte que les evidències més fefaents comencen amb l'inici de la història i, per tant, de la mà de l'escriptura. Feliçment, ja al principi de la civilització, són recurrents els textos de diferent magnitud i estil on veiem com afloren qüestions relacionades amb el més enllà o amb el sentit de la vida. El més antic de tots els que han arribat als nostres dies és l'Epopeia de Guilgameix, datada el 2.500 aC. Aquesta llegenda relata com, després de la mort d'Enkidu, Guilgameix se'n va a cercar la immortalitat i la troba quan Uta-Napixtim li revela que li serà atorgada per una planta aquàtica que habita a les profunditats de l'Eufrates:

En el fons de l'aigua hi ha una planta semblant a l'arç negre i que punxa, com el roser, i et fereix les mans; si els teus dits l'agafen, posseiràs la immortalitat! Guilgameix, després de sentir aquestes paraules, va lligar gruixudes roques als seus peus, es va enfonsar fins al fons de les aigües i arrencà la planta, encara que aquesta ferí la seva mà; després tallà els llaços que amarraven les pedres als seus peus i tornà a la riba. (Botero, 2004: 154)

És per això que Bostrom situa aquí la primera fita del transhumanisme, precisament a Sumer, a trenc d'alba de la civilització (Bostrom, 2011).

Diferents tradicions de la cultura jueva, de la grega i, més tard, de la cristiana atorgarien a l'ànima un caràcter transcendent i perenne, alhora que esgrimien les debilitats, la vulneració $i$ la finitud del cos humà, que va arribar a ser interpretat com una cel.la. Per tant, a partir del moment en què els textos sagrats són esculpits a la roca i gravats en papir, podem trobar constants i recurrents fonts històriques que aborden la temàtica de l'espiritualitat i la possibilitat d'una altra vida, i que per aquest motiu es poden connectar amb el H+. En un lloc primordial per a la civilització occidental, destaca la Bíblia, que, com el $\mathrm{H}+$, també amaga una cosmovisió concreta sobre el model d'home: la de l'home jueu (Antic Testament) i la de l'home cristià (Nou Testament). Observem, doncs, com cadascuna de les diferents cosmovisions es connecten, d'una manera o d'una altra, amb la transcendentalitat, valor fonamental, si bé des d'una altra perspectiva, en la cosmovisió transhumanista.

Per tant, tot i que l'Epopeia de Guilgameix bé pot esdevenir un dels primers precedents històrics d'immortalitat, certament aquesta idea no es va quedar ancorada en l'àrea mesopotàmica, ja que la transcendentalitat esdevindria un tret immanent característic de l'ésser humà. Segles més tard, pensadors grecs com Pitàgores o Plató, si bé des d'una altra perspectiva, també atribuïen aquesta qualitat a l'ànima, com queda patent en la qüestió de la transmigració. Així 
mateix, els jueus i després els cristians també la utilitzarien per justificar la permanència i la continuïtat de la vida després la mort.

En aquesta reconstrucció històrica per la tradició del $\mathrm{H}+$, no podem passar per alt la contribució al coneixement de la Grècia antiga, ja que va ser en les polis gregues on l'escullera de la història posa en marxa el pensament de la cultura occidental. D’alguna manera, serà aquesta tradició, iniciada fa més de 2.500 anys, la que després de ser envernissada per l'humanisme, el racionalisme, el mètode científic, la cibernètica i tot un seguit de capes afegides al llarg dels segles i mil.lennis posteriors acabarà donant llum i forma al transhumanisme.

En primer lloc, trobem l'inici de la filosofia a Grècia, amb els presocràtics, quan un conjunt de pensadors comencen a intentar explicar el món que els envolta a través de la raó i de mites que guardaven una visió ordenada de la natura. La premissa, avui en dia acceptada, que el món té un sentit (mecanisme) que pot ser desxifrat a través de les qualitats i habilitats intel.lectuals en benefici o perjudici de qui ho faci forma part, per tant, de l'herència clàssica. Aquest sentit implica necessàriament un funcionament (mecanisme). La naturalesa no s'explica com a fruit de l'atzar, segueix unes lleis, uns patrons i unes pautes en què intervenen una gran multiplicitat de variables, i sovint es conceben els déus com la força major que coordina i disposa aquestes variables.

Tanmateix, els grecs no aparten la ficció, la imaginació o la fantasia del seu discurs. Així, la literatura grega combina sovint els elements verídics amb els fantàstics, $\mathrm{i}$ els mites i les faules esdevenen narratives pedagògiques de primer ordre (Duch Álvarez, 2015: 18). Aquests mites, malgrat provenir de la ficció, tenien repercussions ben òbvies en les accions dels homes i les dones que havien estat educats amb aquests principis, com en el cas paradigmàtic d'Alexandre el Gran, que, lligat a la tradició homèrica, pensava que era descendent del mateix Aquil.les i que la sang de l'heroi corria per les seves venes. Guardant les oportunes distàncies, el $\mathrm{H}+\mathrm{i}$ el mateix relat que l'envolta també es faran valer de la inventiva per fer possibles algunes de les imaginacions més rocambolesques i, conseqüentment, construir sobre la realitat tangible un sistema ple d'utopies tecnocràtiques que cercaran materialitzar-se al llarg dels anys següents.

La diferència entre la cultura grega i el transhumanisme en el modelatge de la persona que busca perfeccionar-se a través de l'ideal és clara. Quan la literatura (en aquest cas a la Ilíada) projecta un model o un exemple, la seva incidència real quedarà limitada a la predisposició i la voluntat del lector o de l'oient a integrar-la. En canvi, en les ficcions transhumanistes, serà la persona que dissenyi i projecti el model la que decidirà fins a quin punt arriba la seva implementació i influència sobre l'ésser que assumeixi incorporar-la.

Com podem veure, els transhumanistes cerquen copsar l'essència de la vida per mitjà de la seva particular aproximació al món (duta a terme gràcies a la ciència), i redefinir-la, controlar-la, influenciar-la o manipular-la. Aquesta essència és la mateixa que Plató ens diu que no se'ns pot revelar per culpa de les nostres limitacions, perquè l'ésser humà només és capaç de copsar les distorsions de la realitat que veu en les ombres de la caverna (Martínez, 1991). 
Per tant, la tecnologia tindrà un paper destacat a l'hora d'ajudar la humanitat a apropar-se a tot ideal a què no podria arribar per ella mateixa. Aprofitant la metàfora platònica, el $\mathrm{H}+$ entén que serà l'aposta per la tecnologia la que traurà la humanitat de la caverna i la vincularà amb l'essència del món de les idees mitjançant la seva materialització.

Tampoc podem deixar de banda el mite de Prometeu (Gual, 1979), que tantes vegades els transhumanistes han volgut portar a escena. Segons la tradició grega, Prometeu va ser un tità que, després d'ajudar el seu germà Epimeteu a crear la humanitat, va robar una guspira del carro del foc i va atorgar a la humanitat el domini i control sobre aquest element. Aquesta acció va despertar la ira i la fúria de Zeus, ofes per la gesta de Prometeu. Així doncs, per castigar tota la humanitat va fer que el seu fill Hefest creés Pandora, que va destapar la capsa dels mals i els va escampar pel món terrenal. Després que Prometeu es vengés de Zeus ridiculitzant-lo per la terrible acció duta a terme per Pandora, el Déu de déus va ordenar a Hefest que l'encadenés a una pedra al peu d'una muntanya del Caucas. Cada vegada que Prometeu escalava la muntanya, apareixia una àliga i li devorava el fetge, fet que no matava el tità, ja que era immortal, però sí que el feia tornar als peus de la muntanya arrossegat pel pes de la pedra, condemnat a la mateixa sort al llarg de tota l'eternitat, fins que Hèracles el va salvar del terrible destí matant l'àliga amb una fletxa.

Es fa òbvia l'analogia entre el mite de Prometeu i el missatge transhumanista: si Prometeu va robar el foc als déus per il.luminar la humanitat i permetre el seu desenvolupament, els transhumanistes cercaran desxifrar els secrets de la natura gràcies a la tecnologia i ordenaran el seu coneixement en dades amb l'objectiu de provocar un avenç tan gran per a la humanitat que estigui a l'alçada del que va aconseguir el tità grec. En el cas del $\mathrm{H}+$ el progrés desembocaria en un canvi evolutiu en hibridar la humanitat amb la tecnologia (Prados, 2016).

No és anodí que el foc fos un dels primers instruments tecnològics que van implicar un salt qualitatiu de gran transcendència en alguns valors com són la seguretat, a l'hora d'espantar o caçar feres, o la confiança promoguda vers la constatació que l'Homo sapiens era l'única espècie capaç de dominar-lo. Així, els avenços transhumanistes també promouen més seguretat, per via del control dels dispositius tecnològics, i confiança en projectar un model d'individu capaç d'adaptar-se als temps frenètics. Segons els transhumanistes (encarnats en Prometeu), s'aconseguirà extreure (robar) el coneixement (metaforicament objectivat en el foc) de la natura (déus) per enlluernar i fer progressar la humanitat. Els transhumanistes, però, si s'esdevé aquesta gesta, aspiren a abandonar la seva condició terrenal i consolidar-se com a déus, per estalviar-se així la ira divina i deslliurar-se del terrible càstig al qual es va veure abocat Prometeu.

Si unim aquest imaginari de l'univers, la vida i els mites a la concepció grega de la veritat, equiparable a un descobriment o una revelació, podem continuar esgrimint la línia que torna a lligar el $\mathrm{H}+$ a la Grècia clàssica. Els transhumanistes entenen, també, que els misteris que l'univers atresora (la veritat) han de ser explorats i estudiats, si bé en la nostra era sota els ulls de 
la ciència com a últim producte de la professionalització de la raó (guardiana de la veritat mitjançant la fiabilitat del mètode científic), amb l'objectiu de rebel.lar els secrets i algoritmes de la vida.

Cal apuntar, de manera breu, que va ser la tradició hel.lenística, hereva de la clàssica, la que va dedicar temples al saber en forma de biblioteques que van interconnectar un món que fins aleshores estava segmentat. Aquestes biblioteques, on es copiaven i transcrivien diferents obres d'arreu (un precedent de globalització cultural), van constituir veritables punts neuràlgics del coneixement i van propiciar grans avenços en diferents àrees del saber. Per exemplificar-ho, tenim l'obra d'Eratòstenes (Cirene, $276 \mathrm{aC}$ - Alexandria, $194 \mathrm{aC}$ ), que va passar llargues hores a la llegendària biblioteca d'Alexandria i va assolir grans fites per al coneixement com el càlcul, amb una alta precisió, de la circumferència de la Terra (Salinas, 2002).

Ja per acabar, apuntarem que la preocupació per l'estudi i la comprensió del món que van demostrar els nostres avantpassats grecs i que es va refinar arran de la tradició hel-lenística, però també la noció de transcendència que nia en l'ésser humà des del nomadisme, és el que ha dut els transhumanistes a les portes de la posthumanitat. Per tant, potser hem de considerar que l'inici de la seva tradició es troba en els principis de la humanitat (o de la civilització).

\section{Consideració final}

Després d'argumentar les tres tesis apriorísticament antitètiques entre si, només ens agradaria apuntar que aquesta aparent contradicció és fruit de la falta d'acord a l'hora de definir el transhumanisme, com també del seu caràcter ontològic. Si l'entenem com un producte més de la societat actual (com a corrent polític, social o cultural), no el podrem desvincular de la postmodernitat.

Això no obstant, si fem referència a l'anhel de l'ésser humà per projectar el seu propi destí i situar-se al centre del cosmos, haurem de remuntar-nos al Renaixement, quan s'inicia la via que porta a la posthumanitat, per veure on es comencen a establir les bases del transhumanisme. Per acabar, si ens fixem en l'anhel de transcendència de la humanitat, en el seu relat i en les diferents manifestacions que s'hi projecten, podem entendre que el pensament transhumanista esdevé, d'una manera o d'una altra, atemporal i consubstancial a l'ésser humà.

Per finalitzar aquest assaig, apuntarem que res és més contingent $\mathrm{i}$ imprevisible que el futur. Si bé en aquest text s'ha traçat un camí recorregut per la humanitat, no és menys cert que aquesta ruta no és l'única existent, ni l'única per la qual es pot continuar transitant. Malgrat que la humanitat es troba, en l'actualitat, immersa en una nova revolució tecnològica, no tenim cap evidència que el transhumanisme i el posthumanisme siguin les pròximes parades de la seva destinació. 


\section{Referències bibliogràfiques}

Alighieri, Dante (2000). Divina Comèdia. Barcelona: Editorial Proa.

Botero, Jean (ed.) (2004). La epopeya de Gilgamesh. El gran hombre que no quería morir. Madrid: Akal.

Bostrom, Nick (2011). «Una historia del pensamiento transhumanista». Argumentos de Razón Técnica, 14, 157-191.

- (2003). Intensive Seminar on Transhumanism. New Haven: Yale University, 26/6/2003.

Castillo Gómez, Antonio (2002). En el viñedo del texto. Libro y lectura en la universidad medieval. Madrid: Cuaderno del Instituto Antonio de Nebrija.

Cortina, Albert (2017). Humanismo avanzado. Para una sociedad biotecnológica. Madrid: Ediciones Teconte.

Delgado Ramos, Gian Carlo (2012). «Geoingeniería, apuesta incierta frente al cambio climático». Estudios Sociales. Revista de Alimentación Contemporánea y Desarrollo Regional, 20, 213-236.

Descartes, René (1996). Discurs del mètode. Barcelona: Edicions 62.

- (2008). Meditacions metafísiques. Barcelona: Edicions de 1984.

Duch Álvarez, Lluís (2015). «Mito y pedagogía». Praxis \& Saber, 6, 15-29.

Einstein, Albert (1995). Sobre la teoría de la relatividad especial y general. Madrid: Alianza.

Fedorov, Nikolái (1970). Filosofiaya Obshchago Dela: Stati, Mysli, i Pisma Nikolaia Fedorovicha Fedorova. Londres: Gregg Press.

Fullat, Octavi (2003). «Heidegger o los valores rasos de la educación postmoderna». Revista Española de Pedagogía, 225, 209-221.

García Farrero, Jordi; Turró Ortega, Guillem i Vilanou Torrano, Conrad (2016). «El deporte europeo en la crisis del siglo xx. Un palimpsesto posmoderno". Ars Brevis, 22, 304-351.

Gual, Carlos (1979). Prometeo: mito y tragedia. Madrid: Ediciones Peralta.

Haraway, Donna (1984). Manifiesto Ciborg: el sueño irónico de un lenguaje común para las mujeres en el circuito integrado. Recuperat de $<\mathrm{http}: / / \mathrm{reposi}$ torio.ciem.ucr.ac.cr/jspui/handle/123456789/81> [data de consulta: $13 / 3 / 2019]$.

HeIDEGGer, Martin (2000). Carta sobre el humanismo. Madrid: Alianza Editorial.

Kurzweil, Ray (2015). La singularidad está cerca. Cuando los humanos trascendamos la biología. Madrid: LolaBooks.

La Mettrie, Julien Offray de (1983). L’home màquina. Barcelona: Editorial Laia.

LYOTARD, Jean-François (2004). La condició postmoderna: informe sobre el saber. Barcelona: Angle Editorial.

Martínez, Juan José (1991). La fábula de la caverna: Platón y Nietzsche. Barcelona: Ediciones Península.

Nietzsche, Friedrich (1983). Aixi parlà Zaratustra. Barcelona: Edicions 62.

Pico della Mirandola, Giovanni (2001). Discurs sobre la dignitat de l'home. Barcelona: Edicions 62. 
Pigem, Jordi (2018). Angeles o robots. La interioridad humana en la sociedad hipertecnológica. Barcelona: Fragmenta Editorial.

Prados, Mónica (2016). «De Prometeo al Ciberprometeo». Nexus Comunication, 188-223.

<https://doi.org/10.25100/nc.v0i20.1841>

Salinas, Augusto (2002). "Eratóstenes y el tamaño de la Tierra (s. III aC)». Revista de Geografia Norte Grande, 29, 143-148.

SAnvisens, Alexandre (1984). La cibernética de lo humano. Barcelona: OikosTau.

Vesalius, Andeas (1543). De humani corporis fabrica. Basilea: Johannes Oporinus.

WaUthion, Ernesto (1998). "Crítica a la postmodernidad y al neoliberalismo. Una aproximación al pensamiento de Franz J. Hinkelammert». Realidad: Revista de Ciencias Sociales y Humanidades, 62, 157-184.

Ferran Sánchez Margalef és professor associat de la Universitat de Barcelona (UB) del Departament de Teoria i Història de l'Educació, professor col-laborador de la Universitat Oberta de Catalunya (UOC) i professor-tutor de la Universidad Nacional de Educación a Distancia (UNED). En aquestes universitats, imparteix docència en assignatures de política, ètica, teoria de l'educació i pràctica educativa. La seva recerca està focalitzada en àrees com l'epistemologia educativa, la història i filosofia de l'educació o el transhumanisme, temàtica sobre la qual ha realitzat la tesi doctoral: Axiologia i Pedagogia en la cosmovisió transhumanista: una aproximació fenomenològica i hermenèutica.

Ferran Sánchez Margalef is an associate professor at the University of Barcelona (UB) in the Department of Theory and History of Education, a collaborating professor at the Universitat Oberta de Catalunya (UOC) and a tutor professor at the Universidad Nacional de Educación a Distancia (UNED). At these universities, he teaches subjects in politics, ethics, educational theory and educational practice. His research is focused on areas such as educational epistemology, the history and philosophy of education or transhumanism, a topic on which he has completed his PhD: Axiology and Pedagogy in the transhumanist worldview: A phenomenological and hermeneutic approach. 